\title{
Campylobacter: fluoroquinolone resistance in Latin-American countries ${ }^{\#}$
}

\author{
Campylobacter: resistencia a fluoroquinolonas en países latinoamericanos \\ H Fernández ${ }^{a^{*}}$, G Pérez-Pérez ${ }^{\mathrm{b}}$
}

\begin{abstract}
Campylobacter jejuni and $C$. coli are zoonotic bacteria recognised as a major cause of human gastroenteritis and frequent cause of bacterial food-borne illness around the world. A great variety of food-producing animals, especially poultry are important reservoir involved in their spread to humans. Campylobacter gastroenteritis is generally a self-limiting disease avoiding antimicrobial prescription but, when antibiotic therapy is indicated, erythromycin and fluoroquinolone are the drugs of choice. However, Campylobacter has become increasingly resistant to fluoroquinolones with high isolation rates among human and animal strains. This review shows and discusses the data generated in Latin America in relation to fluoroquinolone resistance in Campylobacter highlighting that i) fluorquinolone resistant strains are reported with high frequencies in several countries; ii) the available data allows to confirm that human infection by fluoroquinolone-resistant Campylobacter are originated mainly from the food chain animals and environmental sources; iii) Campylobacter isolation, identification and antimicrobial susceptibility testing have been performed with different analytical methods making necessary the harmonisation and standardisation of diagnostic methods and iv) strengthening Campylobacter antimicrobial resistance surveillance programs and capacity building with the association between public health services and the academic world are necessary.

Key words: Campylobacter, fluoroquinolone, resistance, Latin-America.
\end{abstract}

RESUMEN. Campylobacter jejuni y C. coli son bacterias zoonóticas reconocidas como causa importante de gastroenteritis en humanos y agente frecuente de infecciones alimentarias en todo el mundo. Una gran variedad de animales productores de alimentos para consumo humano, especialmente aves, son importantes reservorios involucrados en su transmisión al ser humano. La gastroenteritis por Campylobacter es generalmente autolimitada, dispensando la prescripción de antibióticos, pero cuando la terapia antibiótica es necesaria, la eritromicina y las fluoroquinolonas son los antimicrobianos de elección. Sin embargo, Campylobacter a llegado a ser cada vez más resistente a fluoroquinolonas, con altas tasas de aislamiento, tanto en seres humanos como en animales. Esta revisión muestra y discute los datos generados en América Latina con relación a la resistencia a fluoroquinolonas en Campylobacter destacando que i) cepas resistentes a fluoroquinolonas son reportadas con altas frecuencias en diversos países; ii) los datos disponibles permiten confirmar que la infección humana por Campylobacter resistentes a fluoroquinolonas se origina principalmente por fuentes animales y ambientales; iii) el aislamiento, la identificación y las pruebas de susceptibilidad antimicrobiana para Campylobacter han sido realizadas mediante diferentes métodos analíticos haciendo necesarias la armonización y estandarización de los métodos diagnósticos y iv) es necesario fortalecer los programas de vigilancia de la resistencia antimicrobiana en Campylobacter y las capacidades diagnósticas, con la asociación entre los servicios de salud y las instituciones académicas.

Palabras clave: Campylobacter, fluoroquinolonas, resistencia, Latinoamérica.

\section{INRODUCTION}

Campylobacter jejuni and C. coli are curved-shape, Gram-negative, thermophilic and microaerophilic bacteria that are recognised as a major cause of human gastroenteritis around the world. As zoonotic bacteria, they are a frequent cause of bacterial food-borne illness with a great variety of animals as their natural reservoir. Poultry is an important reservoir from a public health point of view, due to the fact that they are food-producing animals involved in the spread of Campylobacter to humans (WHO 2001, Engberg 2006, Fernández and Oval 2013).

The incidence of Campylobacter infections has been measured in many industrialized nations varying

\section{Accepted: 14.01.2016.}

${ }^{a}$ Institute of Clinical Microbiology, Universidad Austral de Chile, Valdivia, Chile.

${ }^{b}$ Langone Medical Center, New York University, New York, USA.

*Corresponding author: H Fernández; hfernand@ @uach.cl

${ }^{\#}$ Grants S-2001-33, S-2007-37 DID-UACh and FONDECYT 1110202 from 13/100,000 in the United States to 48.6/100,000 in European countries (CDC 2011, Gauci and Ammon 2007, EFSA 2012). However, in developing countries, where Campylobacter infection is endemic due to poor sanitation, close contact with animals, and environmental sources like water (Fernández 2011), comprehensive surveillance studies on Campylobacter are rare (Zaidi et al 2012). Although, scarce data from developing countries suggest that Campylobacter infections contribute to a considerable human disease burden (Fernández 2011) also associated to increasing isolation rates of antimicrobial resistant strains (Ruiz-Palacios 2007, Pollett et al 2012).

\section{CAMPYLOBACTER AND FLUOROQUINOLONE RESISTANCE}

Campylobacter gastroenteritis is generally a self-limiting disease where antimicrobial treatment is not recommended except in severe, prolonged, systemic infections or in case of infections occurring in elderly, very young, immunocompromised or pregnant individuals (Smith and Fratamico 
2010). When antibiotic therapy is indicated, erythromycin and fluoroquinolone are the drugs of choice (Engberg 2006, 2010). However, Campylobacter has become increasingly resistant to fluoroquinolones (Engberg et al 2001, Moore et al 2006, Ruiz-Palacios 2007).

An alarming increase in Campylobacter fluoroquinolone resistance has been documented in many countries (Pollett et al 2012). This increase emerged after the licensure of fluoroquinolones (sarafloxacin and enrofloxacin) for use in poultry and in general veterinary medicine (Ruiz-Palacios 2007). Several investigations have demonstrated that an increased prevalence of fluoroquinolone resistance among animals and human Campylobacter isolates is temporally related to the use of fluoroquinolones in veterinary medicine (Smith and Fratamico 2010, Engberg et al 2001, Moore et al 2006, Ruiz-Palacios 2007, Pollett et al 2012, Nelson et al 2007, Endtz et al 1991).

The surveillance of fluoroquinolone resistance in Campylobacter is systematically conducted in some industrialised countries where important levels of resistance $(>10 \%)$ were identified in strains isolated from retail chicken meat ${ }^{1}$. Since year 2000, several Latin American countries are part of the PAHO Network for Monitoring/ Surveillance of Antibiotic Resistance but very few of them are conducting surveillance for Campylobacter (Pan American Health Organization 2011). Thus, most of the data generated in Latin America on fluoroquinolone resistance in Campylobacter are mainly sporadic efforts by academic research groups.

In South America, the first attempts to determine the antimicrobial resistance epidemiology of Campylobacter were conducted in $C$. jejuni and $C$. coli strains isolated from hens in Southern Chile in 1989, where no resistance was observed. In another study, conducted in 1992, none of the $C$. jejuni and C. coli strains isolated from children, hens, dogs, river water, aquatic birds and chicken livers were resistant to ciprofloxacin (WHO 2001). Later, in 1995, during a survey of Campylobacter in faecal samples of pigs, dogs and cats, Campylobacter was isolated from 57 samples $(32.2 \%)$; 4 strains (3 C. jejuni and 1 C. coli) $(7.1 \%)$ were resistant to nalidixic acid. All the nalidixic acid resistant strains showed cross resistance to ciprofloxacin, norfloxacin and enoxacin by the agar dilution method (ADM) and by the quantitative method of Wilkins and Thiel (MIC $>40 \mu \mathrm{g} / \mathrm{ml}$ ). In the same region, $12.5 \%$ of C. jejuni strains isolated from hens in 1999 were resistant to ciprofloxacin through the E-test method (WHO 2001) but no fluoroquinolone resistant strains among pediatric populations were recovered between 1996 and 1997 (Fernández et al 2000).

1 CIPARS, Canadian Integrated Program for Antimicrobial Resistance Surveillance. 2011. Emergence of Ciprofloxacin-Resistant Campylobacter in Retail Chicken in British Columbia and Saskatchewan. http://www.phac-aspc.gc.ca/cipars-picra/bulletin-eng.php
In the same period, as cited in the Report and Proceedings of the WHO Consultation of Experts "The Increasing Incidence of Human Campylobacteriosis" (WHO 2001), C. jejuni strains resistant to ciprofloxacin $(50 \%)$ and norfloxacin were isolated from the central region of Chile (Santiago). In Lima (Peru), however, 78\% of the $C$. jejuni isolated from clinical cases showed to be resistant to ciprofloxacin by the ADM. In Buenos Aires (Argentina) $59.6 \%$ of $C$. jejuni and $49.1 \%$ of the $C$. coli strains isolated from a pediatric hospital were simultaneously resistant to both ciprofloxacin and norfloxacin. During the same period, in a study carried out in the city of La Plata (Argentina) all the strains isolated from chicken livers were resistant to norfloxacin and, in addition, $C$. jeuni and $C$. coli floroquinolone resistant strains were isolated from porcine aborted fetuses and amniotic fluid (WHO 2001). At that time, all the reports from South America showed that fluoroquinolone resistance was associated with nalidixic acid resistance. Thus, the importance of nalidixic acid susceptibility testing is no longer useful for identification purposes. However, it could be used as a screening method to measure the emergence and prevalence of fluoroquinolone resistant campylobacters. Using this method in Southern Chile, Fernández and Vera (unpublished data) found that all nalidixic acid resistant (NAR) strains were also resistant to ciprofloxacin by the ADM. They examined a total of 623 samples, of which 201 $(32.3 \%)$ were positive for Campylobacter spp. The highest isolation rate was obtained from hens $(66.7 \%)$, followed by pelicans $(58.3 \%)$, sparrows $(45.0 \%)$, stray dogs $(35.0 \%)$ and chicken livers $(32.2 \%)$ samples. The lowest isolation rates were obtained from humans $(13.3 \%)$ and river water (10.0\%) samples. Of the 201 Campylobacter spp. strains, $126(37.3 \%)$ were C. jejuni and 75 (36.3\%) C. coli; 73 $(36.3 \%)$ were NAR, with $49(24.8 \%)$ corresponding to C. jejuni and 24 (11.9\%) to C. coli. The highest isolation rates of NAR strains were obtained from chicken livers for human consumption $(67.6 \%)$, followed by river water $(60.0 \%)$, pelicans $(40.0 \%)$, stray dogs $(37.1 \%)$ and hens $(27.5 \%)$, samples. The lowest NAR strain isolation rates were obtained from humans (11.8\%) and sparrows (7.4\%) samples (table 1). A recent study, performed in 141 healthy pet dogs, showed that the isolation rate of ciprofloxacin resistant campylobacters $(13.9 \%)$ was lower than that found in stray dogs (Fernández and Oval 2013). These results and those summarised in table 1 show that fluoroquinolone resistant campylobacters can be isolated in this region from humans, domestic animals, food of avian origin, wild birds and environmental water.

Recently, in the Metropolitan Region of Chile, ciprofloxacin resistant Campylobacter strains were isolated from humans with gastroenteritis (60\%), chickens (58.2\%) and bovines (18.2\%). PFGE patterns of these strains showed that 11 shared the same resistance profiles. From them, four human isolates showed indistinguishable PFGE profiles with strains isolated from poultry and one from 
Table 1. Isolation of nalidixic resistant Campylobacter strains from different origins in Southern Chile.

Aislamiento de cepas de Campylobacter nadixilico resistentes provenientes de distintos orígenes en el sur de Chile.

\begin{tabular}{|c|c|c|c|c|c|c|}
\hline ORIGIN (n) & $\begin{array}{c}\text { Campylobacter }+ \\
\mathrm{N} \%\end{array}$ & $\begin{array}{l}\text { C. jejuni } \\
\mathrm{N} \%\end{array}$ & $\begin{array}{l}\text { C. coli } \\
\mathrm{N} \%\end{array}$ & $\begin{array}{c}\text { NAR Campylobacter } \\
\mathrm{N} \%\end{array}$ & $\begin{array}{c}\text { NAR } C . \text { jejuni* } \\
\text { N } \%\end{array}$ & $\begin{array}{c}\text { NAR C. coli* } \\
\text { N } \%\end{array}$ \\
\hline Pelicans (60) & 3558.3 & 2160.0 & 1440.0 & 1440.0 & 720.0 & 720.0 \\
\hline Hens (60) & 4066.7 & 2665.0 & 1435.0 & 1127.5 & 615.0 & 512.5 \\
\hline Sparrows (60) & 2745.0 & 1763.0 & 1037.0 & 27.4 & 27.4 & 00 \\
\hline Humans (128) & 1713.3 & 1270.6 & 529.4 & 211.8 & 211.8 & 00 \\
\hline Dogs (100) & 3535.0 & 1542.9 & 2057.1 & 1337.1 & 38.6 & 1028.6 \\
\hline River water (100) & 1010.0 & 770.0 & 330.0 & 660.0 & 550.0 & 110.0 \\
\hline Chicken livers (115) & 3732.2 & 2875.7 & 924.3 & 2567.6 & 2464.9 & 12.7 \\
\hline TOTAL (623) & 20132.3 & 12662.7 & 7537.3 & 7336.3 & 4924.8 & 2411.9 \\
\hline
\end{tabular}

NAR = nalidix acid resistant $*$ = all NAR strains were resistant to ciprofloxacin.

bovine sources (González-Hein 2013). Earlier, García et al (2009), in the same region reported that $32.4 \%$ of the $C$. jejuni strains isolated from gastroenteritis were resistant to ciprofloxacin.

In recent years, more information about fluoroquinolone resistance has been generated in different Latin American countries. In 2012, Pollet et al (2012) reported that between the years 2001 and 2010, fluoroquinolone resistance has increased in three regions of Peru. In Lima, Cusco and Iquitos isolation of ciprofloxacin resistant $C$. jejuni strain increased from 73.1 to $89.8 \%$, from 72.6 to $82.8 \%$ and from 24.1 to $48.9 \%$, respectively. In the same period, similar increases in ciprofloxacin resistance were observed among $C$. coli strains, from 48.1 to $88.4 \%$ in Lima, from 10 to $65.9 \%$ in Cusco and from 19.5 to $30 \%$ in Iquitos.

In Brazil, Aquino et al (2002) reported that 25\% and $18.2 \%$ of the Campylobacter strains isolated from humans and animals were resistant to norfloxacin and to ciprofloxacin, respectively, using the disc diffusion method. Modolo et al (2003), using the same method, did not find enrofloxacin resistant strains among diarrheic and diarrhea-free dogs, whereas Kuana et al (2008), using ADM, reported resistance to enrofloxacin (71\%) and norfloxacin (14\%) in Campylobacter strains isolated from broiler flocks.

In Argentina, Pantozzi et al (2010), studying the antimicrobial resistance of bacteria isolated from domestic animals, found ciprofloxacin resistant Campylobacter strains in pigs ( $3 / 5$ strains) and dogs ( $1 / 5$ strains). Notario et al (2001) compared eight quinolone resistant $C$. jejuni strains isolated from humans with diarrheal disease with 23 isolates from chicken and from laying hens using RAPDPCR. Three of the five RAPD-PCR patterns obtained were found in both poultry and human isolates, confirming the animal to human transmission. In the city of Cordoba, 69 out of 93 (74\%) Campylobacter strains isolated from diarrheic human faeces during 2006 to 2008 were resistant to ciprofloxacin (Fuentes et al 2010). Tamborini et al (2012) reported ciprofloxacin resistance in $65 \%$ of Campylobacter strains isolated from humans, dogs and chickens and seven genetic subtypes were observed among a sub-set of 13 C. jejuni isolates by PFGE. Two subtypes found among patients matched with the genetic subtypes isolated from their respective dogs. Another subtype recovered from one isolate of human origin matched with two isolates from the patient's chickens.

Zaidi et al (2012) in Mexico, conducted a surveillance study on the prevalence and antimicrobial resistance of Campylobacter isolates collected from 65 different cities during 2003-2006 through an active and integrated food chain surveillance system for Salmonella, Campylobacter and Escherichia coli. Ciprofloxacin resistant $C$. jejuni were found in chickens $(85.8 \%)$, swine $(62.5 \%)$, cattle $(39.8 \%)$ and humans (58.2\%). The authors stated that the high resistance rates to ciprofloxacin preclude the use of fluoroquinolones for treatment of campylobacteriosis in Mexico; it is likely that other Latin American countries are facing similar situation.

In Southern Ecuador, Simaluiza et al (2015), using the EUCAST disc diffusion method, reported that $90.9 \%$ of the $C$. jejuni and all the $C$. coli strains isolated from chicken livers for human consumption were resistant to ciprofloxacin. In the same region, Toledo et al (2015), isolated Campylobacter in $7(10 \%)$ out of 70 dog samples collected in several public parks of Loja city. From them, $4(5.7 \%)$ were $C$. jejuni and $3(4.3 \%) C$. coli and they all were resistant to ciprofloxacin.

The expansion of the aquaculture industry in Chile has been paralleled by an escalated use of antibiotics in fish farming, creating an eventual major risk for development of antibiotic resistance in fish and zoonotic pathogens related to aquatic environments. In fish farming the quinolones oxolinic acid and flumequine are extensively used to treat various fish infections. Salmon aquaculture is one of the major growing and exporting industries in Chile. Its development was accompanied by the use of large amounts 
of antimicrobials, such as quinolones, tetracycline and florfenicol. Milano et al (2011), performed a comparative analysis of the amounts of quinolones consumed in salmon aquaculture with those used in human medicine and reported that the excessive antibiotic use in aquaculture could be an important selective pressure for antibiotic resistant bacteria in the environment. A total of 1,193 mT of quinolones and fluoroquinolones for human medicine and veterinary medicine were imported into Chile between 2000 and 2007. From these 1,193 mT, 9\% were destined for use in human medicine, while the other $91 \%$ was for veterinary use (enrofloxacin $7 \%$ and norfloxacin $4 \%$ ) and aquaculture use (flumequine $46 \%$ and oxolinic acid $34 \%$ ).

This excessive use probably may facilitate selection of resistant aquatic bacteria and others bacteria of medical importance associated with marine activity. Miranda et al (2013) referred that various point mutations in the quinolone resistance-determining regions of the gyrA and/ or parC genes have been detected in quinolone-resistant strains of fish pathogens such as Aeromonas hydrophila, Vibrio anguillarum, V. parahaemolyticus and Edwardsiella tarda. These bacteria have also been associated to human infections. On the other hand, Campylobacter species have been isolated from both aquatic birds and shellfish, among them $C$. jejuni and $C$. coli, that could also carry resistance to quinolones ${ }^{2}$ (Fernández 2014). As previously mentioned, Milano et al (2011) stated that the excessive use of antibiotics in the marine environment in aquaculture is not innocuous and can potentially affect negatively the protocols of therapy of bacterial infections of humans and animals of human interest.

The available data in Latin American countries allows us to confirm that colonization and human infection by fluoroquinolone-resistant Campylobacter are originated from animals and environmental sources, mainly from the food chain.

The high frequency of fluorquinolone resistant strains reported in several Latin American countries could generate a major risk for travelers' diarrhea in subjects coming from more industrialized countries. Foreign travel is a well-known risk factor for acquiring quinolone-resistant Campylobacter infections. This could be directly related to the high frequency of resistant strains and the higher risk of infection in the different under-developed countries (Ekdahl and Giesecke 2004, Kassenborg et al 2004, Vlieghe et al 2008).

Campylobacter isolation, identification and antimicrobial susceptibility testing from the different Latin American countries have been performed with different analytical methods like E-test, the double dilution method, the quantitative method of Wilkins and Thiel, the CLSI and the EUCAST disk diffusion methods (Fernández et al 2000, WHO 2001, Garcia et al 2009, Simaluiza et al 2015). The latter makes comparison of results more

2 Fernández and Vera, unpublished data. difficult, emphasizing the need for harmonization and standardization of diagnostics methods. The Vet-04-A4 and the Vet CAST documents from CLSI and EUCAST represent a way of solution to the problem of defining the breakpoints for Campylobacter strains of animal origin.

Furthermore, most of the reports were conducted by researchers located in the academic world instead of the national public health services, reflecting a lack of prepared personnel and a proper operating of surveillance networks in addition of a partially sampling of the sources of epidemiological interest that are to be studied. Additionally, the small number of reports mentioned here also reflected the lack of interest in Campylobacter surveillance by the Ministries of Health, because it is not considered a priority in their programs and there is not a systematic surveillance of Campylobacter. It is necessary to build capacities. Both activities, harmonization and standardization of analytical methods and building capacities of surveillance networks, could be done through the PAHO Network for Monitoring/ Surveillance of Antibiotic Resistance and other networks such as the WHO Global Food Borne Infection Network, in association with the academic world.

\section{CONCLUSIONS}

The following can be concluded:

- Fluoroquinolone resistance in Campylobacter isolated from human beings, domestic and food-producing animals, food of avian origin, wild birds and environmental sources is common in several Latin American countries.

- There are evidences that food-producing animals and food chain are important steps in the transmission of fluoroquinolone resistant strains.

- Different analytical methods have been employed for the isolation, identification, typing and resistance assessment, making comparison of results difficult and indicating the need for harmonization and standardization of diagnosis methods.

- Systematic surveillance of fluoroquinolone resistance in Campylobacter is necessary to be implemented in Latin-American countries and Network for Monitoring/ Surveillance of Antibiotic Resistance, other networks and capacity building need to be strengthened.

- To improve the diagnostic capabilities and capacity building, associations between public health services and the academic world should be established.

\section{REFERENCES}

Aquino MHC, ALL Filgueiras, MCS Ferreira, SSD Oliveira, MC Bastos, A Tibana. 2002. Antimicrobial resistance and plasmid profiles of Campylobacter jejuni and Campylobacter coli from human and animal sources. Lett Appl Microbiol 34, 149-153.

CDC. 2011. Vital Signs: Incidence and trends of infection with pathogens commonly transmitted through food - Foodborne Diseases Active Surveillance Network, 10 U.S. sites, 1996-2010. MMWR 60, 749-55. 
Ekdahl K, J Giesecke. 2004. Travellers returning to Sweden as sentinels for comparative disease incidence in other European countries, Campylobacter and Giardia infection as examples. Euro surveillance: Europ Comm Dis Bull 9, 6-9.

Endtz HP, GJ Ruijs, B van Klingeren, WH Jansen, T van der Reyden, RP Mouton. 1991. Quinolone resistance in Campylobacter isolated from man and poultry following the introduction of fluoroquinolones in veterinary medicine. J Antimicrob Chemother 27, 199-208.

Engberg J, Aarestrup, DE Taylor, P Gerner-Smidt, I Nachamkin. 2001. Quinolone and macrolide resistance FM in Campylobacter jejuni and C. coli: resistance mechanisms and trends in human isolates. Emerg Infect Dis 7, 24-34.

Engberg J. 2006. Contributions to the epidemiology of Campylobacter infections. A review of clinical and microbiological studies. Dan Med Bull 53, 361-389.

European Food Safety Agency. 2012. The European Union summary report on trends and sources of zoonoses, zoonotic agents, antimicrobial resistance and foodborne outbreaks in 2010. EFSA J 10, 2597.

Fernández H, M Mansilla, V González. 2000. Antimicrobial susceptibility of Campylobacter jejuni subsp. jejuni assessed by E-test and double dilution agar method in Southern Chile. Mem Inst Oswaldo Cruz 95, 247-249.

Fernández H. 2011. Campylobacter and Campylobacteriosis: a view from South America. Rev Peru Med Exp Salud Publica 28, 121-127.

Fernández H, A Oval. 2013. Occurrence of Campylobacter jejuni and Campylobacter coli biotypes and antimicrobial susceptibility in healthy dogs in Southern Chile. Acta Scientiae Vet 41, 1100.

Fernández H. 2014. Campylobacter: aspectos epidemiológicos y resistencia a los antimicrobianos. Una perspectiva desde América Latina. Resúmenes del Congreso Latinoamericano de Microbiología, Cartagena de Indias, Colombia, en Hechos Microbiológicos 5, supl 2.

Fuentes LS, M Bottiglieri, C Amieva, S Barril. 2010. Prevalence and susceptibility profiles of Campylobacter spp isolated from diarrhea. Serie Gastroenterol 12, 2-5.

García P, N Valenzuela, MV Rodríguez, E León, H Fernández. 2009. Antimicrobial susceptibility of Campylobacter jejuni isolates from stool cultures in Santiago, Chile. Rev Chil Infectol 26, 511-514.

Gauci A, A Ammon. 2007. The first European communicable disease epidemiological report. European Centre for Disease Prevention and Control, Stockholm, Sweden.

González-Hein G, N Cordero, P García, G Figueroa. 2013. Molecular analysis of fluoroquinolones and macrolides resistance in Campylobacter jejuni isolates from humans, bovine and chicken meat. Rev Chilena Infectol 30, 135-139.

Kassenborg HD, KE Smith, DJ Vugia, T Rabatsky-Her, MR Bates, MA Carter, NB Dumas, MP Cassidy, N Marano, RV Tauxe, FJ Angulo. 2004. Fluoroquinolone-resistant Campylobacter infections: Eating poultry outside of the home and foreign travel are risk factors. Clin Infect Dis 38, S279-S284.

Kuana SL, LR dos Santos, LB Rodrigues, A Borsoi, HL de Souza Moraes, CT Salle, VP do Nascimento. 2008. Antimicrobial resistance in Campylobacter spp isolated from broiler flock. Braz J Microbiol 39, 738-740.

Milano A, M Barrientos, C Gómez, A Tomova, A Buschmann, H Dölz, F Cabello. 2011. Injudicious and excessive use of antibiotics:
Public health and salmon aquaculture in Chile. Rev Med Chile 139, 107-118.

Miranda CD, A Tello, PL Keen. 2013. Mechanisms of antimicrobial resistance in finfish aquaculture environments. Front Microbiol 4, 233.

Modolo JR, R Giuffrida, C Lopes. 2003. Antimicrobial susceptibility of 51 Campylobacter strains isolated from diarrheic and diarrhea-free dogs. Arq Inst Biol São Paulo 70, 283-286.

Moore JE, MD Barton, IS Blair, D Corcoran, JS Dooley, S Fanning, I Kempf, AJ Lastovica, CJ Lowery, M Matsuda, DA McDowell, A McMahon, BC Millar, JR Rao, PJ Rooney, BS Seal, WJ Snelling, O Tolba. 2006. The epidemiology of antibiotic resistance in Campylobacter. Microbes Infect 8, 1955-1966.

Nelson JM, TM Chiller, JH Powers, FJ Angulo. 2007. Fluoroquinoloneresistant Campylobacter species and the withdrawal of fluoroquinolones from use in poultry: A public health success story. Clin Infect Dis 44, 977-980.

Notario R, N Borda, T Gambande, J Bermejo, A Ponessa, V Toledo. 2011. Quinolone resistant Campylobacter jejuni strains isolated from humans and from poultry. Medicina (Buenos Aires) 71, 331-335.

Pan American Health Organization. 2011. Annual Report of the Network for Monitoring/Surveillance of Antibiotic Resistance-2008. Rev Patol Trop 40, 1-112.

Pantozzi FL, FA Moredo, GB Vigo, GI Giacoboni. 2010. Antimicrobial resistance in indicator and zoonotic bacteria isolated from domestic animals in Argentina. Rev Argent Microbiol 42, 49-52.

Pollett S, C Rocha, R Zerpa, L Patiño, A Valencia, M Camiña, J Guevara, M López, N Chuquiray, E Salazar,-Lindo, C Calampa, M Casapia, R Meza, M Bernal, D Tilley, M Gregory, R Maves, E Hall, F Jones, CS Arriola, M Rosenbaum, J Pérez, M Kasper. 2012. Campylobacter antimicrobial resistance in Peru: a ten-year observational study. BMC Infect Dis 12, 193.

Ruiz-Palacios GM. 2007. The health burden of Campylobacter infection and the impact of antimicrobial resistance: Playing chicken. Clin Infect Dis 44, 701-703.

Simaluiza RJ, Z Toledo, S Ochoa, H Fernández. 2015. The prevalence and antimicrobial resistance of Campylobacter jejuni and Campylobacter coli in chicken livers used for human consumption in Ecuador. J Anim Vet Adv 14, 6-9.

Smith JL, PM Fratamico. 2010. Fluoroquinolone resistance in Campylobacter. J Food Prot 73, 1141-1152.

Tamborini AL, LM Casabona, MR Viñas, V Asato, A Hoffer, MI Farace, MC Lucero, A Corso, M Pichel. 2012. Campylobacter spp.: prevalencia y caracterización fenogenotípica de aislamientos de pacientes con diarrea y de sus mascotas en la provincia de La Pampa, Argentina. Rev Arg Microbiol 44, 266-271.

Vlieghe ER, JA Jacobs, M Van Esbroeck, O Koole, A van Gompel. 2008. Trends of norfloxacin and erythromycin resistance of Campylobacter jejuni/Campylobacter coli isolates recovered from international travelers, 1994 to 2006. J Travel Med 15, 419-425.

WHO, World Health Organization. 2001. The increasing incidence of human Campylobacteriosis. Report and Proceedings of a WHO Consultation of Experts. Copenhagen. WHO/CDS/CSR/APH/2000.4.

Zaidi MB, PF McDermott, FD Campos, R Chim, M Leon, G Vázquez, G Figueroa, E López, J Contreras, T Estrada-García. 2012. Antimicrobial-resistant Campylobacter in the food chain in Mexico. Foodborne Path Dis 9, 841-847. 
